\title{
Nonlinear Analysis for Steel Lined Reinforced Concrete Penstock
}

\author{
Ji Dongyu \\ Hunan Urban Construction College \\ Xiangtan, China \\ hnjdy@126.com
}

\author{
Li Lamei \\ North China University of Water Resources and \\ Electric Power \\ Zhengzhou, China \\ 834178464@qq.com
}

\begin{abstract}
Steel lined reinforced concrete penstock is commonly used as a hydraulic structures in recent years. Because of the complex structure of the penstock, so far no design specification can follow at home and abroad. In this paper, general finite element calculation software is used to conduct nonlinear analysis, the stress of the steel liner with the increased internal pressure variation elastoplastic distribution of outsourcing concrete and the development law of joints cracked concrete for the penstock of Yisa River Station II. Analysis shows that, the steel lined reinforced concrete penstock design of the I I Hydropower of Yi Sa

river is reasonable, pressure piping structure will not crac $k$ occurred in the design load, the structure meet the stren gth requirements, the deformation values of pressure pipel ines is small and meet the stiffness requirements. The desi gn of structural is economical, safe and reliable.
\end{abstract}

Keywords- Steel lined reinforced concrete; Penstock; Nonlinear analysis; Stress distribution; Analysis section.

\section{SUMMARY}

Yisa River Station II is located in Yuanjiang County, Yunnan Province, and the total installed capacity is 25MW. Plant water flow is $3.6 \mathrm{~m}^{3} / \mathrm{s}$ and the biggest work stress of pressure pipeline is $994 \mathrm{~m}$ water head. Most of the catch-water pipeline is out steel tube structure, but the end of main pipeline uses steel lined reinforced concrete pipe structure, and the steel pipe radius is $1.0 \mathrm{~m}$. The designed internal pressure of pipe is $9.94 \mathrm{MPa}$, and the depth of internal steel lining of pressure pipe is $22 \mathrm{~mm}$. It uses steel plate $16 \mathrm{MnR}$, and the elasticity modulus is $210 \mathrm{GPa}$, the yield strength $330 \mathrm{MPa}$. The depth of outsourcing of reinforced concrete is $0.4 \mathrm{~m}$, and the upside of it is thick wall cylinder, the central angle of it is $210^{\circ}$, and the downside is the connection of the flat base and the foundation. Its strength grade of concrete is $\mathrm{C} 25$, and the grade of rebar is II. Tangent modulus of elasticity is $200 \mathrm{GPa}$, and the Poisson's ratio is 0.25 [1], yield strength of it $310 \mathrm{MPa}$, the secant Young's modulus 20GPa, and two layers of reinforcement is used at the ring. The diameter of the inlayer is $28 \mathrm{~mm}$ and the number is 9 , and the outer layer's is $22 \mathrm{~mm}$ and the number is $8[2]$.

\section{Calculation Model}

\section{A Subject Investigated}

In engineering calculation program, the reinforcement ratio of reinforced concrete by volume is approximately $3.745 \%[3]$. The initial gap between the pipe and the surrounding concrete is designed of $0.55 \mathrm{~mm}$ to actual engineering data and in accordance with relevant provisions, to simulate the effects of construction, temperature changes and concrete creep[4].

\section{B Model Element}

In outsourcing concrete nonlinear computational analysis, the use of SOLID65 element, which is designed for concrete, rocks and other non-uniform material that compressive strength is much greater than the tensile strength and the development of element[5-6]. The element can also be used in other areas, such as reinforced composite materials (such as glass fiber) and geological materials (such as rocks). The element has eight nodes. Each node has three degrees of freedom. Steel liner with 4 nodes to simulate housing element, each element node has six degrees of freedom. Steel liner and the gap of concrete wrapped left is connected by the spring element[7-8].

\section{Steel Model}

Analysis using distributed steel model, the model assumes that the reinforcement distributed in the entire element by confirm angular, and assuming that a good bond between the concrete and steel, in which assumptions, element consists of a uniform continuous material, which can deduced comprehensive concrete and the element stiffness matrix contribution of steel[9]. Distributed reinforcement model commonly used in the wall, deep beams and other structures, this model uses the plane stress assumptions. By defining concrete element volume to consider the role of steel reinforcement ratio, this model can be use easily and can meet the needs of engineering precision.

\section{Finite Element Model}

When using the finite element method analysis the pressure piping structure[10], the pressure pipe and structural finite element simulation range is divided as shown in Fig .1 and Fig .2. 


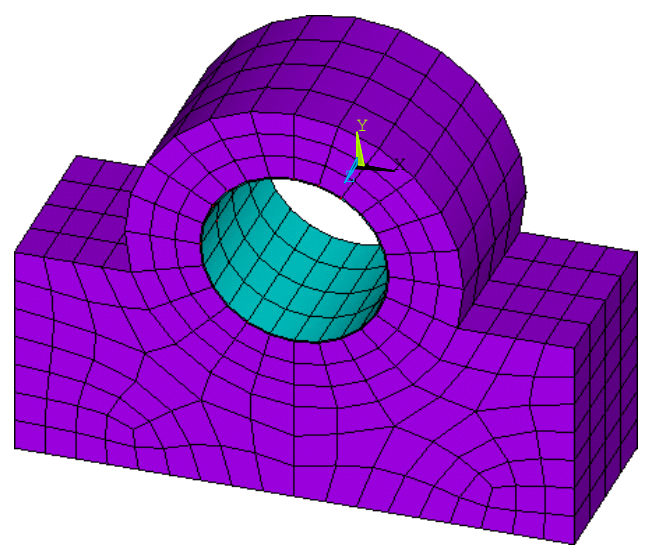

Figure 1. The FEM division of pressure pipe

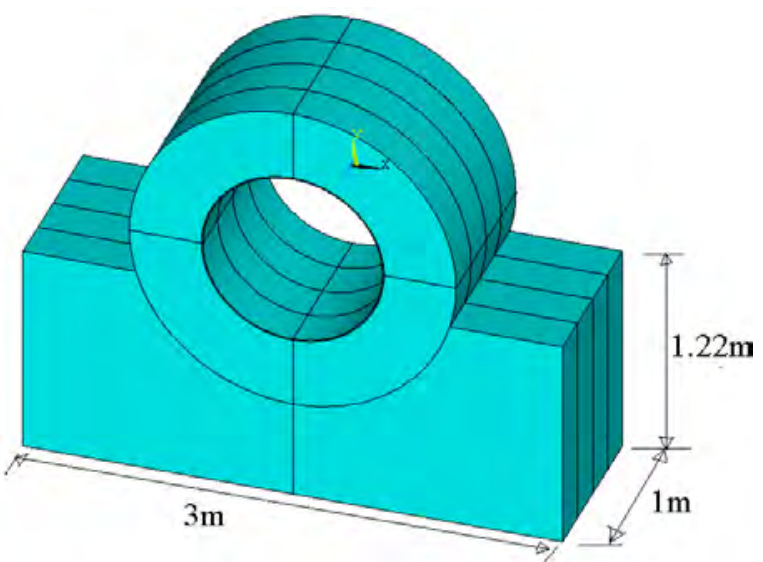

Figure 2. The simulation range of pressure pipe model

III.

IV. STRUCTURAL ANALYSIS OF PRESSURE PIPE

\section{A Analysis of the Section}

When using the three-dimensional nonlinear finite element analysis of the steel lined and reinforced concrete penstock from the Yi Sha he river hydropower

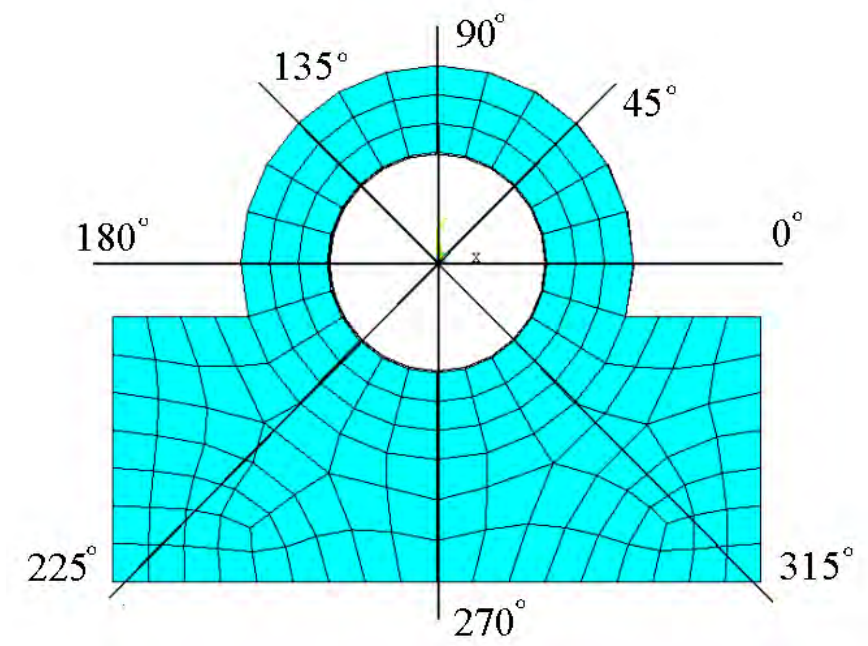

Figure 3. The sectional view of Penstock's analysis station, we should remove the cross section shown in Fig .3. 


\section{B Process Analysis of Cracking}

The results show that with the increase in the water pressure, pressure piping structure mainly has the following stages:

(1) $0<\mathrm{P} \leq 10.134 \mathrm{MPa}$, The internal water pressure entirely is born by the steel-lined, but the concrete does not work because in the water pressure at the inner steel liner radial displacement has not filled the gap of $0.55 \mathrm{~mm}$, which is that the steel liner and the concrete do not completely contact so that all the internal forces completely are composed by the steel. When $\mathrm{P}$ is $10.134 \mathrm{MPa}$, the gap between the steel liner and the concrete full contact, then if we continue to increase the pressure on this situation, the internal forces will pass through the spring element to transfer the surrounding concrete with together working by the concrete and steel liners.

(2)In the situation of stress between 10.134MPa and $13 \mathrm{MPa}$ with about 45 degree angle, the local fractures appear in the interior of the concrete. But the fractures in
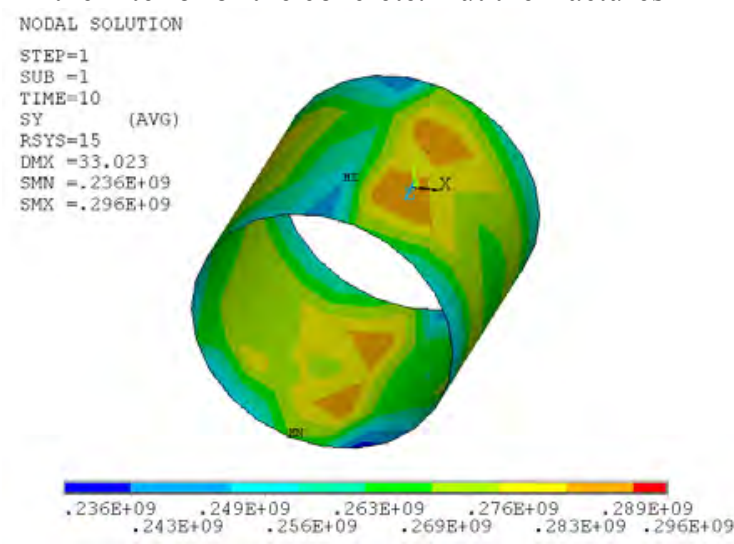

Figure 4. Steel liner circumferential stress cloud (Internal pressure:13MPa)
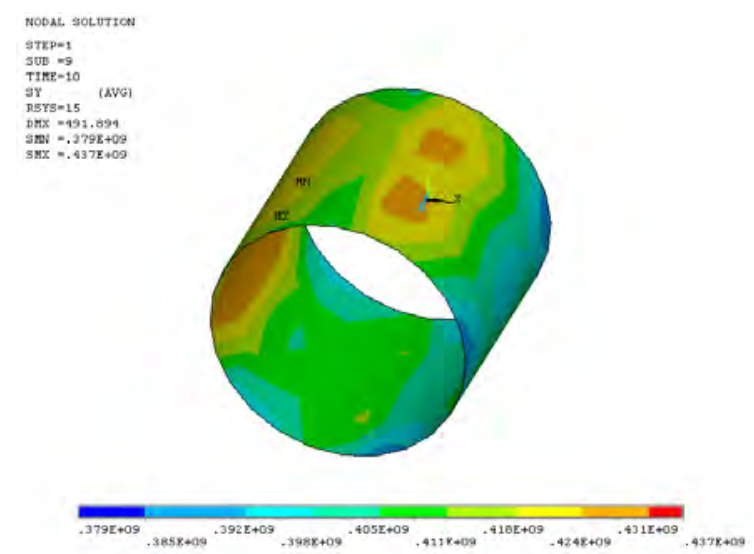

Figure 6. Steel liner circumferential stress cloud (Internal pressure:19MPa)

As can be seen from Fig .4 to Fig .7, the value of circumferential stress in the steel liner is gradually increased with the increase of the inside water pressure,the maximum stress on the surrounding this situation is only small part of it and don't develop cracked stripes.

(3)In the situation of stress between $13 \mathrm{MPa}$ and $17 \mathrm{MPa}$, the first cracked fractures appear in the surface of concrete located in 45 degree angle as well as the first cracked stripe. At the same time, the buckling of concrete enters the part plastic state.

(4) In the situation of stress between $17 \mathrm{MPa}$ and $19 \mathrm{MPa}$, at the top of concrete pipe during 45 and 135 degree angle, many fractures appear. Those fractures are cracked fractures. At the same time, the concrete enter the fully plastic state and already have been broken without capacity of bearing internal water pressure. The stress of $19 \mathrm{MPa}$ is the ultimate bearing capacity of steel liner and concrete joint bearing.

\section{Stress Analysis}

At the given water pressure the pipe circumferential stress behind the dam and the surrounding concrete pressure are shown in Fig .4 to Fig .7.

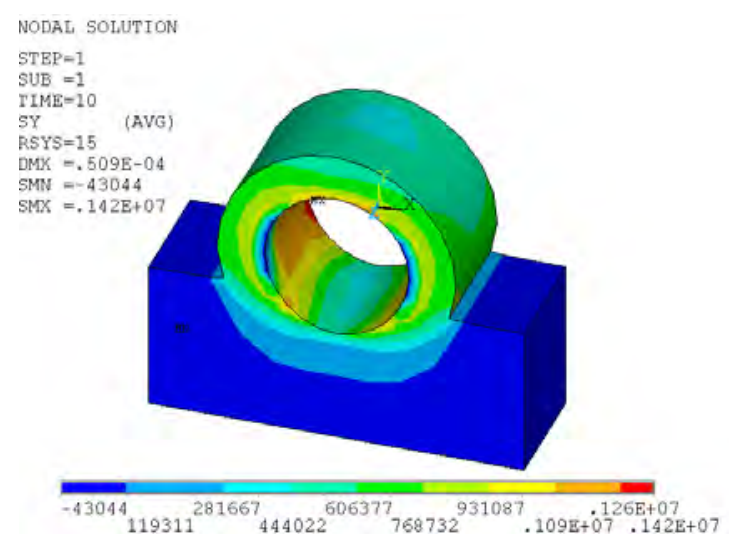

Figure 5. Concrete circumferential stress cloud

(Internal pressure:13MPa)

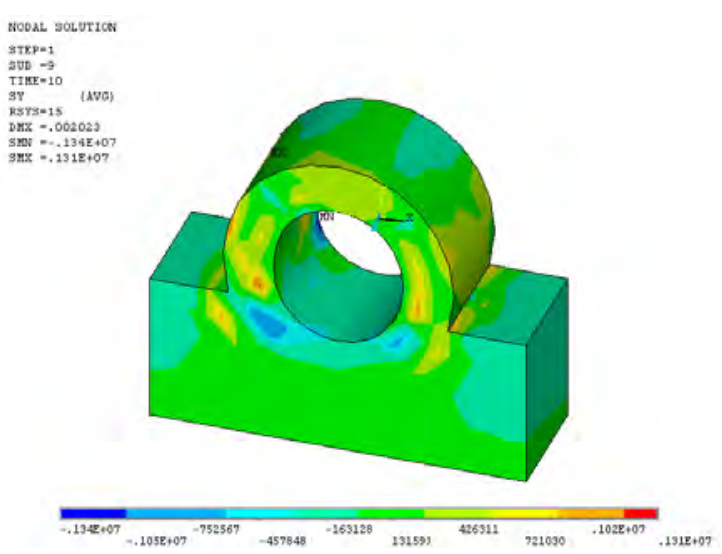

Figure 7. Concrete circumferential stress cloud (Internal pressure: $19 \mathrm{MPa}$ )

concrete extend outward from the inner surface, which is mainly due to cracking of the concrete, inner stress is gradually released, the maximum stress gradually extended to the outer ring. 


\section{CONCLUSION}

In summary,the steel lined reinforced concrete penstock design of the II Hydropower of Yi Sa river is reasonable, pressure piping structure will not crack occurred in the design load, the structure meet the strength requirements, the deformation values of pressure pipelines is small and meet the stiffness requirements. The design of structural is economical, safe and reliable.

\section{REFERENCES}

[1] SL191-2008. Design Code for Hydraulic Concrete Structure[S]. China Water Conservancy and Hydropower Press, 2008.

[2] Hegao Wu, Wei Zhang. Study on wall thickness of steel lined reinforced concrete penstock laid on downstream surface of dam [J]. Journal of hydraulic engineering, 2006, 37(9):1085-1091.

[3] Wei Zhang, Hegao Wu. Safety evaluation of the joint between steel lined reinforced concrete penstock laid on downstream face of dam [J]. Rock and soil mechanics, 2010,31(3):799-804.
[4] Congbao Wang, Hegao Wu. Comparison Analysis of Elasticity Center Method and Finite Element Method for Penstock Laid on Downstream Surface of Dam [J]. Water resources and power, 2005,23(4):8-11.

[5] Bofang Zhu. Finite Element Method Principle and Application [M]. China Water Conservancy and Hydropower Press, 1998.

[6] Suohong Jiang. Application of the elasticity center method of structure mechanics for penstock laid on the downstream face of dam [J]. Water power, 2003,29(9):31-34.

[7] Xucheng Wang. Finite Element Method [M]. Tsinghua University Press, 2003.

[8] Min Xia. Research on the crack width formula of steel lined reinforced concrete penstock laid on downstream surface of dam [J]. Concrete, 2011,(9):36-39,43.

[9] Jianjing Jiang, Xinzheng Lu, Lieping Ye. Finite Element Analysis of Concrete Structures [M]. Tsinghua University Press, 2004.

[10] Shanding Ma, Ruze Wang. Hydropower Station Structures (The Second Edition) $[\mathrm{M}]$. China Water Conservancy and Hydropower Press, 1996. 